\title{
A RESPONSABILIDADE PENAL DA PESSOA JURÍDICA NO SISTEMA ITALIANO
}

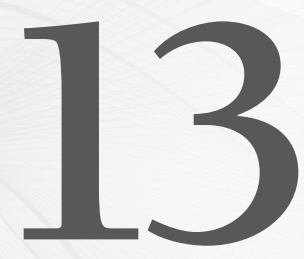

\author{
Criminal liability of legal entity in italian system
}

\section{Maristella Amisano Tesi}

Doutora e Professora de Direito Penal na Università della Calabria, Italia.

Recebido em: 29.07.2012

Aprovado em: 02.09.2012

ÁreA do DiReITo: Internacional; Penal

Resumo: Este trabalho pretende fornecer uma visão geral do instituto italiano da responsabilidade da pessoa jurídica. Durante muito tempo a tradição italiana impediu a instituição de qualquer forma de responsabilidade da pessoa jurídica e, quando a legislação internacional e, no específico, a comunidade europeia, pressionaram para introduzir uma responsabilidade do ente, o legislador italiano não foi pronto e acabou fazendo uma lei que apresenta vários pontos obscuros.

Começando do tipo de responsabilidade da pessoa jurídica. 0 decreto que introduziu a responsabilidade definiu a mesma como administrativa, mas algumas caracteristicas, e as modalidades de aplicação, sugeriram à doutrina que o tipo de responsabilidade é de fato criminal. 0 mesmo legislador, aumentando a confusão, no relatório
ABSTRACT: This work aims to provide an overview of the Italian institute of the responsibility of the legal entity. For a long time Italian juridical tradition has prevented the establishment of a form of liability for legal entities. For that reason, when the international law and, specifically, the European community forced to introduce one kind of responsibility, the Italian legislator wasn't prepared and ended up making a law with many obscure points.

Starting from the nature of this kind of responsibility. The decree that introduced this responsibility defined it as administrative, but some of its characteristics and the procedural way for applying it suggested the doctrine that it is actually a kind of criminal liability. The legislator itself, adding confusion to confusion, in the prefatory part of the decree spoke about tertium 
ao decreto falou da forma de responsabilidade como de tertium genus, ou seja, não totalmente criminal nem totalmente administrativa.

As dificuldades começam a partir da natureza da responsabilidade, mas não terminam aí.

0 decreto instituiu um mecanismo muito complexo para identificar a culpa do ente.

0 presente trabalho, após ter analisado as questões sobre a natureza da responsabilidade do ente e os elementos necessários para essa culpabilidade, examina os sujeitos envolvidos, as sanções e os crimes pressupostos da responsabilidade, visando a individualização dos aspectos problemáticos e peculiares de um instituto muito controverso no ordenamento italiano.

Palavras-chave: Pessoa jurídica - Responsabilidade - Modelos de organização - Ente. genus responsibility, not totally criminal neither totally administrative.

Problems start from nature of liability but do not end there.

The decree established a very complicated mechanism to identify the responsibility of the legal entity.

This document, after analyzing many issues about the nature of this kind of responsibility, will examine the involved subjects, the sanctions, the crimes at the base of the liability, trying to highlight problematics and peculiars aspects of one of the most controversial Italian institutes.

KeYWords: Legal entity - Responsibility - Liability - Compliance programs.

SumÁRıo: 1.0 debate - 2. 0 Decreto Legislativo 231/2001 - 3. A natureza da responsabilidade penal e sua relevância - 4. Os sujeitos - 5 . A relação entre o crime da pessoa física e a responsabilidade da pessoa jurídica -6 . Os elementos objetivos da responsabilidade da pessoa jurídica - 7. 0 elemento subjetivo: pessoas em posição apical e subordinados - 8. Os modelos de comportamento - 9. As sanções - 10. Sinais sobre os crimes pressupostos - 11. Conclusões - 12. Referências.

\section{0 DEBATE}

Tradicionalmente, no direito penal italiano, a responsabilidade penal sempre foi ligada a uma pessoa física e nunca foi relacionada com a pessoa jurídica. A ideia é tão antiga que está resumida em uma máxima latina: societas delinquere non potest.

Já no direito romano acreditava-se que os collegia personalia e collegia realia não fossem ontologicamente preparados, por causa do próprio objetivo de alcançar interesses coletivos e não egoístas, para cometer crimes. Este legado foi preservado, mesmo quando chegada a invenção da pessoa jurídica como fictio juris, diferentemente dos próprios componentes.

Em tempos mais recentes, embora as necessidades sociais pedissem para se impor uma pena aos entes jurídicos como membros inteiros, não apenas como indivíduos que os compõem, algum estudioso identificou como obstáculo intransponível para a responsabilidade criminal da pessoa jurídica o art. 27 da 
Constituição italiana. A Carta fundamental do ordenamento italiano sob o art. 27 prevê que: "a responsabilidade penal é pessoal". O adjetivo pessoal foi entendido como ligado ao indivíduo. Isso negava resolutamente a possibilidade de uma responsabilidade penal das pessoas coletivas. As considerações que foram feitas a partir dessa ideia básica foram muitas. Por exemplo, lembramos as objeções, segundo as quais o direito penal é feito para o homem-sujeito pensante, que pode ser livremente determinado, então, a responsabilidade da pessoa jurídica seria incompatível com o elemento subjetivo das normas penais, que não fariam sentido nenhum quando aplicadas a uma entidade que não seja física.

Subsequentemente, no entanto, a doutrina veio para interpretar o art. 27 da Constituição, conceituando de "responsabilidade pessoal" a própria responsabilidade, aliás, um fato cometido com dolo ou culpa (ou preterintenzione, que é uma forma de elemento subjetivo presente no sistema penal italiano). Com a exceção, em suma, da responsabilidade objetiva. Assim, a pessoa não será apenas física, mas o conceito também estaria aberto à pessoa jurídica. Sem prejuízo dos detratores da responsabilidade da pessoa jurídica, a respeito das considerações relativas ao elemento subjetivo e a função da sanção.

O debate, em tons mais ou menos brilhantes, continua até hoje, apesar da promulgação do Decreto Legislativo 231/2001, que não tocou o coração do problema e deixou, se não todos, muitos insatisfeitos.

\section{0 Decreto Legislativo 231/2001}

Acabamos de descrever o ambiente no direito penal italiano no qual nasceu o decreto, clima que com certeza não estava pronto para introdução de uma responsabilidade estritamente penal das pessoas coletivas. Mas o governo italiano havia ratificado três convenções internacionais que protegem os interesses financeiros da Comunidade Europeia (PIF; Convenção de Bruxelas de 26.07.1995 e 27.09.1996; Primeiro Protocolo de Dublin), que combatem a corrupção de funcionários públicos estrangeiros em transações comerciais internacionais (Convenção da OCDE) e que lutam contra a corrupção em que funcionários estão envolvidos na Comunidade Europeia (Bruxelas, 26.05.1997). Todas essas convenções foram ratificadas pela Lei Delegada 300, de 29.09.2000 que, além de instruir o governo a elaborar um decreto relativo à responsabilidade administrativa das pessoas coletivas, estabeleceu para a aplicação imediata de algumas das regras das convenções internacionais.

A Itália encontrou-se, portanto, num impasse.

Embora o clima cultural não estivesse pronto para aceitar uma responsabilidade verdadeiramente penal das pessoas jurídicas, os compromissos com a Eu- 
ropa empurravam para o estabelecimento uma responsabilidade corporativa, embora não tivessem sido estabelecidos os critérios sobre a forma de acusação desta responsabilidade.

Então, ao final, foi simples manter os compromissos com a Europa, sem tomar uma posição certa sobre a natureza da responsabilidade. Na verdade, a natureza da responsabilidade tem sido definida como administrativa, mas a solução com certeza não pôs todos de acordo.

Estas são as razões pelas quais ainda há divergência sobre a natureza da responsabilidade da pessoa jurídica introduzida pelo Decreto Legislativo 231/2001, nos termos da Lei Delegada 300/2000. A única situação incontroversa é a de que foi introduzida uma forma de responsabilidade punitiva, e isso já constitui um ponto de mudança profunda do sistema.

O mesmo relatório do governo, que acompanha o decreto, destacou que hoje alguns dos eventos criminosos mais perigosos são realizados por pessoas jurídicas, muitas vezes com organizações muito complexas.

O relatório devidamente observa que são robustas as diferenças, nos casos que podem acontecer. Primeiro, há certamente o crime das empresas intrinsecamente ilícitas, que, portanto, tem como objeto a prática de crimes. Em segundo lugar há os casos, felizmente menos frequentes mas, não por isso, menos socialmente perigosos, nos quais a busca de lucro pela empresa pode levar à criação de infrações, até criminosas. Nesse caso, podemos distinguir os crimes que podem recair sob uma política comum, bem como a corrupção, e os crimes que resultam de deficiências organizacionais ou de controle pela gestão de topo, como é no caso da falta de cumprimento com as normas de segurança no trabalho que levem a acidentes. Casos não desconhecidos e que mostram como a empresa deve ser uma entidade independente dos indivíduos que a compõem. Por causa disso o Decreto Legislativo 231/2001 criou uma disciplina repressiva, mas também preventiva, não limitada aos indivíduos, mas que tem, por dizer assim, um duplo centro de imputação: além da pessoa física, a pessoa jurídica.

\section{A NATUREZA DA RESPONSABILIDADE PENAL E A SUA RELEVÂNCIA}

Como dissemos, não existe unidade nos pontos de vista da doutrina italiana a respeito da natureza da responsabilidade do ente estabelecida pelo Decreto Legislativo 231/2001.

Vamos começar do único dado objetivo disponível para nós. O decreto legislativo, na mesma nomeação, define a responsabilidade da pessoa jurídica como administrativa. 
Parece que não devemos ter dúvidas: é o mesmo fator da lei que definiu essa forma de responsabilidade como administrativa, então parecem desnecessárias outras objeções. Mas as coisas não são tão simples assim. Em primeiro lugar porque a nomeação não é sempre útil, para definir: no ordenamento italiano é bem possível que a nomeação de um instituto alude a um conceito ou disciplina contrários ao conteúdo da norma. Por isso, as definições legais são irrelevantes e somente as mesmas regras são capazes de indicar a real natureza de um instituto (Ronco. Responsabilità delle persone giuridiche. In: EG, XXVII. Roma, 2002,3).

Mas esse assunto não mudaria, no nosso caso, as coisas, porque não há, dentro das regras, diretrizes que colocam em dúvida a natureza administrativa. É outro dado que nos leva a duvidar. O relatório ao decreto alude à criação de um tertium genus de responsabilidade: esta é uma forma de extensão do direito penal entendido como "lei punitiva". Com este termo seria incluída tanto a lei penal quanto o direito administrativo no sentido civil-punitivo (MANNA. La c.d. responsabilità amministrativa delle persone giuridiche: un primo sguardo d'insieme. In: RTDPE, 2002).

Este tipo de incerteza no relatório, que dê uma definição clara de responsabilidade administrativa vira por um tertium genus de responsabilidade que cai dentro do direito sancionatório, tem alimentado as dúvidas da doutrina, que em muitos casos não tem apoiado a ideia de uma responsabilidade verdadeiramente administrativa.

Por causa disso, alguém chegou a falar de "fraude nos rótulos".

As posições da doutrina são dispostas ao longo de três direções.

Há aqueles que continuam acreditando que o legislador, ao introduzir uma responsabilidade que é basicamente criminal, queria seguir um caminho, para dizer assim, oblíquo, definindo a responsabilidade como administrativa, mas fornecendo uma regulamentação de fato penal (RoNCO. Responsabilità delle persone giuridiche. In: EG, XXVII. Roma, 2002,3). Traços que se relacionam com a investigação penal no julgamento, que é penal, e do regime das sanções e certas garantias. O relatório do governo, seguido por uma doutrina minoritária, dá origem a um novo tipo de sanção meio penal, meio administrativa: mantém as salvaguardas e o procedimento típico da lei penal, mas não é realmente uma sanção penal, devido à originalidade do sistema que, em vez de ser punitivo, tem fortes fins especiais de prevenção (AMBrosetTi. Efficacia della legge penale nei confronti delle persone. In: La legge penale, a cura di RonCo; ZANiCHELli. Bologna, 2006; CARACCIOLI. Osservazioni sulla responsabilità penale "propria" delle persone giuridiche. In: Studi in onore di Marcello Gallo. Scritti degli allievi. Torino, 2004). Uma terceira posição continua sendo ligada à definição do legislador e considera a responsabilidade administrativa mesmo. Não se trata somente de nomenclatu- 
ra, mas é uma opção que tem fundamento em elementos bem mais significativos do que a própria nomenclatura. A natureza administrativa pode ser inferida a partir do regime de prescrição (peculiar, pois a sua interrupção é regulada pelo Código Civil), a partir do tipo de protesto contra a infração e também a partir da falta de uma taxa de conversão das sanções pecuniárias. Além disso, o ilícito da pessoa jurídica é funcional e não pode ser confundido com o crime da pessoa física, o que constitui um índice que a natureza é realmente administrativa e não penal, especialmente para quem tenha conhecimento da extensão das garantias próprias do sistema penal feita pela Lei 689/1981 às regras administrativas (AMISANO. Il Decreto Legislativo n. 231 dell'8.6.2001. In: Codice Penale Ipertestuale, leggi complementari, a cura di Ronco; Ardizzone. Utet, 2007, 1327ss.).

A variedade das posições doutrinárias não é apenas uma questão de nomenclatura, pois as implicações na prática são significativas. Uma primeira consideração entre as muitas: as disposições penais são apoiadas pelas garantias da Constituição, as normas administrativas não.

\section{OS SUJEITOS}

Saber quais são os sujeitos, sobre quem cai a responsabilidade (e, portanto, as sanções) imposta pela nova legislação é muito importante. É por isso que o legislador, no art. $1 .^{\circ}$ do Decreto, preocupou-se em esclarecer que as regras da responsabilidade se aplicam às pessoas jurídicas e associações, incluindo aquelas sem personalidade jurídica.

A extensão a estes sujeitos demonstra uma intenção política e legislativa muito clara: se incluem as associações sem personalidade jurídica para fortalecer a proteção geral-preventiva. Como se trata de assunto bem importante, o art. 1. ${ }^{\circ}$ do Decreto cuida de esclarecer também, desta vez de forma negativa, quais são as pessoas jurídicas que não devem ser consideradas sujeitas à disciplina. Não são destinatários da nova normativa o Estado, os governos locais, as outras agências públicas e organizações não econômicas e as instituições que tem relevância constitucional.

A exclusão da responsabilidade, em outras palavras, esta relacionada com o Estado e os governos locais e com os entes que não tem função econômica nenhuma, mas que, ao contrário, por definição, tem uma pública autoridade.

A razão para esta exclusão é clara: qualquer multa ou interdição seria impossível, contraproducente, inútil e seria até lançada sobre os cidadãos.

Problemático, no entanto, é o caso dos organismos públicos, porque não existem entes econômicos do tipo que não exercem autoridade oficial, mas que tem gestão como a empresa. Provavelmente o legislador pretendeu manter 
firme a distinção entre os setores público e privado, especialmente pensando nas consequências que teriam resultado em uma interdição em relação a determinados serviços públicos essenciais.

O mais importante é que o legislador procurou definir o mais claramente possível, tanto de forma positiva quanto de forma negativa, o âmbito dos sujeitos aos quais pode ser relacionada uma responsabilidade. O que significa, sem dúvidas, ajudar na execução.

\section{A RELAÇÃO ENTRE O CRIME DA PESSOA FISICA E A RESPONSABILIDADE DA PESSOA JURÍDICA}

Como já mencionamos, a responsabilidade da pessoa jurídica é diferente da responsabilidade dos indivíduos que constituem a pessoa jurídica.

$\mathrm{O}$ ponto de partida para que possam ser desenvolvidos os elementos que levam à responsabilidade da pessoa jurídica é um fato (criminoso) realizado por uma pessoa física que tenha um relacionamento com o ente. Esse fato deve ter todas as características de um crime. Por essa razão é importante entender e definir a relação entre o crime do indivíduo e a assunção da responsabilidade pela pessoa jurídica.

A primeira observação que, além disso, evita muitos problemas de interpretação, é que a responsabilidade não é em concurso: em primeiro lugar porque se trata de responsabilidades diferentes, e também porque o crime do indivíduo é um pré-requisito da responsabilidade da pessoa jurídica, mas é independente dessa e esta sujeita a regras próprias de atribuição. A independência entre os dois eventos também é demonstrada pelo fato que pode existir responsabilidade da pessoa jurídica mesmo que o autor - pessoa física do crime - não tenha sido identificado ou não seja imputável e mesmo se o crime for prescrito.

A conclusão que devemos tirar é que essas são formas diferentes de responsabilidade, são independentes, mas o crime do indivíduo é um pré-requisito indispensável para que possa ser realizada a analise das exigências para imputar à pessoa jurídica uma responsabilidade. Responsabilidades diferentes e, em seguida, independentes, mas relacionadas em termos de pressuposição.

\section{OS ELEMENTOS OBJETIVOS DA RESPONSABILIDADE DA PESSOA JURÍDICA}

$\mathrm{O}$ art. 5. ${ }^{\circ}$ do Decreto estabelece que: "a pessoa jurídica é responsável pelos crimes cometidos em seu interesse ou benefício:

A) por pessoas que são representantes, diretores ou gestores do ente ou de suas unidades organizacionais com autonomia financeira e funcional, bem como pessoas que, de fato, geram e controlam o próprio ente; 
B) por pessoas sob a orientação ou supervisão de uma pessoa referida na alínea $a$ ).

O ente não é responsável, se as pessoas referidas no $\S 1 .^{\circ}$ atuaram exclusivamente no interesse de terceiros.

Esse artigo lista os recursos de investigação, dos quais se pode levar a pessoa jurídica à responsabilidade penal.

A doutrina (Manna. La c.d. responsabilità amministrativa delle persone giuridiche: il punto di vista del penalista. In: CP, 2003; Pasculli. La responsabilità "da reato" degli enti collettivi nell'ordinamento italiano. Profili dogmatici ed applicativi. Bari, 2005) interpretou esse artigo como o que estabelece, numa comparação paralela com a teoria geral do crime, os elementos objetivos da responsabilidade da pessoa jurídica. O primeiro ponto que parece claro é que a responsabilidade pode ser acionada somente se o crime foi cometido no interesse ou benefício do ente: a mesma responsabilidade, portanto, deve ser excluída no caso do empregado que não opera em favor do ente, mas em detrimento do mesmo.

De acordo com o relatório do governo, o elemento do interesse seria "dentro" do infrator: o importante é dar evidência que o empregado agiu motivado pelo desejo de facilitar o ente, aliás, no interesse dele.

A conexão entre o crime e o interesse da pessoa jurídica pode ser imediata ou mediata, ou seja, o crime é cometido imediatamente no interesse da pessoa jurídica ou o crime é realizado durante uma atividade feita dentro de um quadro legal, mas que destina-se a seguir esse mesmo interesse (De Simone. I profili sostanziali della responsabilità c.d. amministrativa degli enti; la "parte generale" e la "parte speciale" del d. lgs. 8 giugno 2001 n. 23. In: La responsabilità degli enti per i reati commessi nel loro interesse. In: CP, 2003, 673).

O relatório do governo define a vantagem em contraste com o conceito de interesse. A vantagem seria o elemento que o ente pode mesmo ter obtido quando o indivíduo não agiu no interesse da pessoa jurídica. Seria, portanto, uma avaliação objetiva realizada a posteriori, independentemente do interesse que motivou o sujeito ativo do crime. É preciso refletir sobre as relações entre os conceitos de vantagem e interesse. À primeira vista pode parecer que os dois termos sejam um pleonasmo: evocariam, de fato, o mesmo conceito. Na verdade, agir com algum interesse significa querer obter uma vantagem. Mas é o mesmo art. 12 do Decreto, a mostrar que os dois termos se referem a dois conceitos diferentes. De fato, o art. 12, alínea 1, letra $a$ ), oferece uma circunstancia atenuante se "o agente tiver cometido o ato nos melhores interesses de terceiros e o ente não tenha obtido uma vantagem ou tenha obtido uma vantagem mínima". 
Aqui interesse e vantagem podem não coexistir e, de fato, se colocam em um sistema de progressão que vai do subjetivo, ou seja, a atitude interna do autor do crime, ao objetivo, ou seja, o que ocorreu na realidade. Os dois conceitos são, portanto, diferentes, mas isso não significa que, na aplicação prática, não possa acontecer uma convergência de interesse e vantagem como característica dos crimes cometidos por uma pessoa física (PASCULLi. La responsabilità "da reato" degli enti collettivi nell'ordinamento italiano. Profili dogmatici ed applicativi. Bari, 2005, 171).

Outra parte da doutrina considera os dois critérios complementares (DE VERo. Struttura e natura giuridica dell'illecito di ente collettivo dipendente da reato. In: RIDPP, 2001, 726): com o interesse é reforçada a perspectiva subjetiva, com a vantagem o dado real. Mas essa definição não muda muito a perspectiva como aquela na qual se considera os dois termos uma hendíade (De Simone. La responsabilità da reato degli enti nel sistema sanzionatorio italiano: alcuni aspetti problematici. In: RTDPE, 2004, 671) e que, de fato, ab-roga a vantagem, considerando como relevante apenas a variável causal do interesse. $O$ interesse não deve ser lido em uma finalização marcadamente subjetiva, mas de conduta objetiva. Vale a pena dizer que a jurisprudência é contrária a essa visão, acreditando que a indicação do legislador de interesse e vantagem não constitua uma hendíade, pois os termos determinam conceitos muito diferentes (Cass. pen. II, n. 3.615 de 20.12.2005).

Qualquer seja o modo de entender a relação entre o interesse e a vantagem, vale a pena notar que estes dois elementos não precisam necessariamente ter um conteúdo econômico direto (Pulitanó. La responsabilità "da reato" degli enti: i criteri di imputazione. In: RIDPP, 2002, 426). O fato que o agente tiver cometido o crime "no exclusivo interesse de terceiros" exclui a responsabilidade do ente. Nesse caso não tem coincidência entre a vontade coletiva e a vontade individual (PAsculli. La responsabilità "da reato" degli enti collettivi nell'ordinamento italiano. Profili dogmatici ed applicativi. Bari, 2005, 170).

\section{O ELEMENTO SUBJETIVO: PESSOAS EM POSIÇÃO APICAL E SUBORDINADOS}

$\mathrm{O}$ art. 5. ${ }^{\circ}$ do Decreto Legislativo 231/2001 que, como vimos, expõe os elementos de imputação objetiva da responsabilidade do ente delimita a mesma responsabilidade aos crimes cometidos por indivíduos que tem uma relação especial com a mesma pessoa jurídica. A responsabilidade, em outras palavras, nasce para todos os crimes cometidos no interesse, ou na vantagem do ente, mas apenas se participar nestes crimes serão pessoas que se enquadram em duas categorias, cuja distinção reflete efeitos muitos importantes na disciplina 
do instituto. As duas categorias estão descritas no art. $5 .^{\circ}$ e são: (a) pessoas que são representantes, diretores que tem a gestão do ente ou de suas unidades organizacionais, com autonomia financeira e funcional, bem como indivíduos que de fato tem a gestão ou o controle das mesmas; e (b) pessoas sob a direção ou supervisão dos sujeitos da letra (a).

$\mathrm{O}$ fato de que o crime foi cometido por um sujeito que cai numa o noutra categoria muda radicalmente o critério da imputação da responsabilidade ao ente. E isso nos leva ao que o relatório do governo chama de critério da imputação subjetiva, ao contrário do critério objetivo indicado no art. $5 .^{\circ}$. Essa imputação subjetiva está descrita nos arts. $6 .^{\circ}$ ou $7 .^{\circ}$, dependendo se a infração for cometida por uma pessoa física que cair em uma ou em outra das categorias indicadas. A responsabilidade da pessoa jurídica é acionada se o crime é relacionado com o ente, não somente no sentido objetivo (porque o crime foi cometido no seu interesse ou vantagem), mas também no nível subjetivo, através de uma falha de organização.

É precisamente por causa desta organização, que o mecanismo funciona de forma diferente: que o ator seja em posição de topo ou em posição subordinada.

Começamos com a análise das matérias referidas na letra a) do art. 5. ${ }^{\circ}$, que são aquelas que se encontram dentro da organização do ente em uma posição superior. Estes temas são, em si mesmos, uma expressão da vontade social, mas as organizações empresariais atuais são tão complexas que exigem uma certa fragmentação de poderes de decisão. Portanto, além dos crimes cometidos pelos dirigentes, foram levados em conta também os sujeitos da letra $b$ ) do art. 5. ${ }^{\circ}$, que se limitam a implementação das decisões do ente, mas a responsabilidade da pessoa jurídica pode existir sob condições diferentes.

No caso de indivíduos em posição apical, é como se a própria instituição tivesse cometido o crime, então o ente não responde, somente se prova que, antes do crime ser cometido, criou modelos organizacionais e de gestão capazes de prevenir crimes da mesma espécie que ocorreu e que os modelos foram atualizados e o ente supervisionou a operação e o cumprimento dos próprios modelos. O ente deve também demonstrar que a verificação de eficácia dos padrões de comportamento tem sido confiada a um organismo da pessoa jurídica com poderes autônomos de iniciativa e de controle. O ente, em suma, no caso de crimes cometidos por indivíduos em posição apical, não responde, só se provar de ter, antes do fato, criado os modelos estabelecidos, destinados a prevenir crimes semelhantes a aquele que ocorreu e se provar que o cumprimento e a atualização e a validade desses modelos tenham sido delegadas a um órgão de fiscalização do ente, que possui certas características e poderes. Na ausência desses elementos, o ente vai responder como responsável. 
Por outro lado, se o crime está cometido por indivíduos subordinados, o ente é responsável se o crime foi possível graças a falhas nas obrigações de direção ou de controle (art. 7. ${ }^{\circ}$ do Decreto).

Este é o princípio, parcialmente compensado por uma série de causas de exclusão da responsabilidade da pessoa jurídica. O ente, de fato, não está em violação das obrigações relativas à gestão e supervisão se, antes do cometimento do crime, adotou, e eficazmente implementou, um modelo de organização e gestão e controle adequado para evitar crimes do tipo que ocorreram. Modelos que devem ser efetivamente implementados, mas disso vamos tratar mais tarde.

As pessoas subordinadas parecem ser capazes de formar um juízo de reprovação menor dentro do ente e, portanto, o ente responde, quando a infração tenha sido possível porque o ente não cumpriu as obrigações de gestão e de supervisão.

O que diferencia mais nitidamente a responsabilidade do ente, consoante o crime tenha sido cometido por uma pessoa apical ou subordinada, é o ônus da prova: no caso do crime cometido por o subordinado o ônus de provar a falta de adoção ou implementação do modelo recai sobre o Ministério Público. Por conta, no caso de crimes cometidos por indivíduos em posição apical, o ente está obrigado a comprovar a preparação atempada dos modelos, a sua implementação e o monitoramento constante realizado pelo órgão competente.

Podemos, nessa altura da analise, entender porque os arts. $6 .^{\circ}$ e $7 .^{\circ}$ são considerados pela doutrina o elemento subjetivo da responsabilidade. O legislador sentiu a necessidade de criar um sistema que, por sua afinidade com o direito penal por causa das sanções aflitivas, respeitasse certos princípios do direito penal e, entre eles, sobretudo a culpa. Para que o ente seja responsável, portanto, é essencial que o crime da pessoa física seja ligado ao ente, não somente ao nível objetivo (porque o crime foi cometido em seu próprio interesse o à sua própria vantagem), mas também ao nível subjetivo, através de um culpado de organização. Culpa de organização que assume aspectos diferentes, quando, ao cometer o crime, é um indivíduo em posição apical dentro do ente ou subordinada. Isto é, porque no caso de crime feito a partir do vértice, a carga de prova é do ente mesmo e fica, nesta maneira, mais pesado. Como já mencionado, o ônus da prova concentra-se na preparação e implementação de medidas adequadas, verificadas através de uma análise detalhada realizada por um organismo que deve possuir determinadas características de comportamento padrão. E são os próprios modelos-padrão de comportamento o fulcro das regras sobre a responsabilidade do ente. 


\section{OS MODELOS DE COMPORTAMENTO}

Antes de abordar os padrões específicos de comportamento que - como vocês já viram - são essenciais para atribuir ou negar a responsabilidade do ente, vale a pena fazer uma observação sobre a natureza da responsabilidade. Nós já abordamos esta questão e já conhecemos as diferenças entre a doutrina sobre a natureza da responsabilidade da pessoa jurídica estabelecida com o Decreto 231/2001. Nessa altura, podemos derivar um conjunto de dados úteis para o propósito de tomar uma decisão sobre a natureza da responsabilidade. Apesar das aparentes semelhanças com o direito penal, há um fato que está em flagrante violação do princípio da reserva absoluta de lei: os padrões de comportamento para evitar o crime são processados pelo mesmo ente. Mas há mais: no caso de crimes cometidos por uma pessoa em posição apical, é o mesmo ente que precisa provar os elementos que já vimos, afim de evitar a responsabilidade. Este também é um princípio estranho ao direito penal, que funda o ônus da prova na acusação. Todos estes elementos nos levam a concluir que a natureza real da responsabilidade do ente é administrativa.

Chegamos agora à descrição dos padrões de comportamento. Primeiro elemento é que a atitude deve ser preventiva, pois é necessário que os modelos forneçam padrões de conduta que reduzam o risco global de atos criminosos. Trata-se, em suma, de regras de cautela "autônomas" porque processadas pelo mesmo ente a fim de conter os crimes penais. Para cumprir este propósito, os modelos devem ser constantemente atualizados: por isso, usando uma terminologia anglo-saxão, diz-se que os modelos devem ser to be e não as is. O modelo deve, é claro, ser eficaz. O problema é verificar a eficiência do modelo: se a prática de um crime constituir totalmente a prova da inadequação do modelo, entraríamos num circulo vicioso, no qual a consumação do crime se revela sempre o fracasso do modelo. Entraríamos, assim, numa espécie de responsabilidade objetiva, sem que se possa ser atribuído ao ente qualquer sinal que evocar a culpa. E então devemos supor que a verificação da eficiência do modelo deve ser feita com o critério do prognóstico póstumo. Só assim a responsabilidade do ente está ancorada à não conformidade com os modelos-padrão.

E quais são esses padrões obrigatórios? Em primeiro lugar, os modelos devem identificar as atividades nas quais crimes podem ser cometidos: trata-se de uma espécie de mapeamento das estruturas em que se analisa quais crimes são mais propensos a ser realizados.

Em segundo lugar, os modelos tem que desenhar protocolos específicos para o planejamento da formação e implementação de decisões do ente em relação à prevenção de crimes. 
Como o legislador esta ciente de que os crimes podem ser evitados apenas com recursos financeiros especificamente dedicados, o próprio ente precisa modelar a forma de gerir recursos financeiros, a fim de prevenir o cometimento de crimes.

Para o modelo ser eficaz, é preciso dar amplo conhecimento dele a todos os funcionários, ativando mecanismos disciplinares em caso de não observância das instruções (AlberTi. Fondamenti aziendalistici della responsabilità degli enti ai sensi del d. lgs. n. 231 del 2001. In: Soc, 2002, 539).

A estes requisitos adiciona-se um sistema de vigilância do modelo. A lei prevê que, além da preparação do modelo de prevenção, o ente tem que providenciar um controle interno por uma agência autônoma. Na verdade, na prática, a criação desta organização criou muitas dúvidas sobre a constituição, os critérios de formação e de responsabilidade dessa instituição de controle. O que é certo, é que o organismo de controle deve ser órgão autônomo e independente, por isso seria mais apropriado que os componentes fossem entidades independentes. Nós não podemos não dar conta das inúmeras críticas que envolveram a negação da responsabilidade do ente que tinha elaborado modelos de organização.

Segundo alguns autores (DE VERO. Struttura e natura giuridica dell'illecito di ente collettivo dipendente da reato. In: RIDPP, 2001, 1142) a função dos modelos de prevenção geral não parece ser compatível com um mecanismo de desculpa. Além disso, cada modelo, para ter eficácia real, deve ser feito com o "temperamento" e a "cultura" da pessoa jurídica, pois deve compreender os mecanismos do próprio funcionamento. $\mathrm{O}$ modelo deve ser uma cruel autoanálise e autocrítica do ente. O que é bastante difícil de verificar.

Além disso, o Decreto prevê a adoção de um modelo que não tem tipificação suficiente: trata-se de uma fórmula vazia que a mesma pessoa jurídica enche de significado. Em resumo, a preparação do modelo é essencial para evitar a responsabilidade do ente, mas essa disposição e a sua eficácia estão longe de ser fácil.

\section{As SANÇÕES}

Assim identificados os itens que constituem a base da responsabilidade do ente, é necessário considerar as sanções. A lista exaustiva das sanções é prevista no art. 9. ${ }^{\circ}$ do Decreto, que afirma: "as sanções por os ilícitos administrativos que dependam do crime são:

A) sanções pecuniárias; 
B) Sanções de interdição;

C) Confisco;

D) Publicação da sentença.

As sanções de interdição de exercício de um direito são:

A) a proibição do exercício da atividade;

B) A suspensão ou revogação de autorizações, licenças ou concessões funcionais pela comissão do crime;

C) A proibição de contratar com o Estado, exceto para o desempenho de um serviço público;

D) A exclusão de subvenções, empréstimos ou subsídios e eventual revogação dos já concedidos;

E) Proibição de publicidade de bens ou serviços."

Está bem claro que há três tipos de sanções: pecuniária, interdição e confisco.

Começamos a analisar as sanções financeiras, que são as sanções básicas, aquelas que se aplicam a todos os ilícitos, enquanto interdição, e confisco, que são aplicados somente se houver uma certa progressão de gravidade.

O mecanismo de aplicação das sanções é muito complexo. O ente está condenado ao pagamento de ações que não podem ser inferior a 100, nem mais de 1000 .

A quantidade de tais ações, no entanto, não é fixa, mas varia entre um valor mínimo e um máximo. O mecanismo de imposição, então, é duplo: ele estabelece a quantidade de ações e estabelece o montante das ações individuais. Os resultados destas duas variáveis darão o valor total da sanção. Este sistema foi concebido para avaliar a gravidade da infração, de acordo com a lógica tradicional. O sistema de comensurar a pena dá para calibrar a eficácia da sanção com as reais condições econômicas da pessoa jurídica. O art. 11 do Decreto estabelece as normas para comensurar a sanção, estabelecendo que o juiz, na determinação do número das ações, deve levar em conta a gravidade da ofensa, o grau de responsabilidade do ente e as atividades feitas para eliminar ou mitigar as consequências do fato, ou para impedir novas infrações. A quantidade de ações, no entanto, é fixada com base nas condições econômicas e financeiras do ente, a fim de garantir a eficácia da sanção. Em resumo, o mecanismo é articulado, mas tem a função de fixar a pena em relação ao próprio elemento de culpa, assim como, com referência a uma aflitividade real e justa da sanção. Justamente para os mesmos fins há também casos de redução da sanção previstos no art. 12 do Decreto: por exemplo, se o condenado cometeu o fato 
nos maiores interesses de terceiros e o ente não obteve nenhum benefício ou obteve um benefício mínimo.

$\mathrm{O}$ art. 13 do Decreto estabelece a interdição, que é aplicável somente a respeito dos delitos para os quais é expressamente prevista e quando existe pelo menos uma das seguintes condições:

A) que o ente ganhou do crime um lucro de tamanho considerável e que a infração tinha sido cometida por pessoas em posição apical ou subordinados, mas, nesse último caso, apenas se o crime tiver sido determinado ou facilitado por sérias falhas organizacionais;

B) Em caso de reincidência dos crimes cometidos.

Está claro que todas as sanções de interdição de direitos são um dos aspectos mais importantes de todo o sistema das sanções. Trata-se de sanções "incapacitantes" (PIEGallini. Sistema sanzionatorio e reati previsti dal codice penale. In: DPP, 2001, 1359) e, portanto, são invasivas e temidas, por isso aplicam-se só aos caso de natureza mais grave.

A duração da interdição depende do tipo de crime e está estabelecida dentro de uma gama entre três meses e dois anos. Somente em casos excepcionais ou nos casos mais graves, indicados no art. 16 do Decreto, pode ser permanente.

O legislador também dita critérios de seleção das interdições. O ponto focal é adaptá-las à máxima função de prevenção, pois será necessário tomar conta de vários fatores, incluindo a atividade específica do ente a qual se refere o crime cometido. Se for necessário, podem ser aplicadas mais sanções de interdição. Pelo contrário, mantendo firme a aplicação de sanções pecuniárias, a interdição não se aplica quando, antes da declaração de abertura do julgamento de 1. ${ }^{a}$ instância, o ente correr nestas condições: (a) o ente compensou totalmente o dano e eliminou todas as consequências danosas ou perigosas, ou o ente trabalhou efetivamente para esse efeito; (b) o ente eliminou as falhas organizacionais que levaram ao crime com a adoção e implementação de modelos organizacionais adequados para prevenir crimes do mesmo tipo do crime que aconteceu; (c) o ente tem devolvido todos os lucros a fim de confisco.

Para evitar a sanção da interdição o ente deve provar a coincidência de todas essas condições. Condições que perseguem sua eficácia em duas linhas: a da prevenção e a da sanção.

Em seguida, o art. 18 dispõe a publicação da sentença, que é uma sanção que pode ser imposta somente se for aplicada uma interdição e que está projetada para tornar a sanção ainda mais aflitiva através da divulgação dessa nos jornais ou postando a sentença no município onde o ente tem a sede. 
A última sanção indicada é o confisco. O art. 19 afirma que: "está sempre disposto na sentença condenatória para o ente, o confisco do dinheiro ou lucro do crime, exceto a parte que pode ser retornada ao lesionados. O ente está sujeito aos direitos adquiridos por terceiros de boa-fé.

Quando não pode ser executado o confisco nos termos do parágrafo $1 .^{\circ}$, pode ser confiscada a mesma quantidade de dinheiro, mercadorias ou outros bens de valor equivalente ao preço do dinheiro ou do lucro".

Vale a pena ter lido a norma, pois dessa forma os leitores podem entender as fortes semelhanças com o instituto do confisco penal, incluindo também o confisco por equivalente, recém introduzido no ordenamento italiano com uma norma mais do que oportuna.

O confisco é obrigatório, o que significa que é muito claro o propósito de evitar que o ente goze dos frutos de um crime que foi cometido no seu interesse ou vantagem.

\section{SinAIS SOBRE OS CRIMES PRESSUPOSTOS}

O esquema que temos identificado e que se relaciona à responsabilidade do ente não se aplica a qualquer tipo de crime cometido no interesse ou vantagem do ente por um sujeito apical ao subordinado. Esse mecanismo ocorre apenas quando for cometido um dos crimes estritamente indicados no Decreto. Por isso, parafraseando a linguagem do direito penal, se fala que o Decreto tem também uma "parte especial", que é uma elevação de crimes. A atitude do legislador, na época da estreia do Decreto, foi mínima, ou seja, foram incluídos na lista exaustiva dos crimes que podem formar a base da responsabilidade somente poucos crimes. Acreditava-se, de fato, que a introdução da responsabilidade do ente já era uma inovação muito grande, de modo à orientar, pelo menos inicialmente, para limitar o âmbito de operação. O objetivo era incentivar o fortalecimento gradual de uma cultura da legalidade.

Por esta razão, os acréscimos na listagem dos crimes foram sucessivos e progressivos, de modo que as mudanças foram mudando até a mesma natureza da parte especial do Decreto.

Tendo em conta estas informações, é bom listar os crimes que podem dar a origem à responsabilidade do ente. Não vamos alongar o nosso discurso analisando cada crime, pois a nossa intenção é apenas informativa, mas a partir de agora podemos já destacar que por algum dos crimes previstos será fácil compreender a importância de se atribuir uma responsabilidade por o ente, para outros, pelo contrário, não se vê a razão pela qual o ente pode ser sancionado. 
O Decreto começa com o crime de recepção ilegal de benefícios, fraudes contra o Estado ou um organismo público ou para obter fundos públicos. A seguir estão os crimes de tratamento ilícito dos dados, o crime organizado, corrupção e suborno, falsificação de dinheiro, cartões de crédito, selos fiscais e ferramentas ou marcas de identificação, crimes contra a indústria e o comércio, crimes corporativos, crimes para fins de terrorismo ou subversão das práticas democráticas, crimes de mutilação genial feminina, crimes contra a pessoa, abuso do mercado. Mais os crimes de morte ou ferimento grave cometidos em violação das regras relativas à proteção da saúde e segurança no trabalho, crime de receptação, lavagem de dinheiro e uso de dinheiro, propriedades ou bens de proveniência ilícita, crimes relativos à violação do direito autoral, crime de indução a não fazer declarações ou fazer declarações falsas no tribunal, crimes ambientais.

Para estes mesmos fatos, sob a forma da tentativa, é proporcionada uma sanção reduzida a respeito do que a forma consumida.

\section{Conclusões}

Nós examinamos o padrão através do qual o ente pode assumir uma responsabilidade administrativa. Tal como já vimos, há questão sobre a natureza da responsabilidade, mas é um assunto a parte. Agora parece apropriado dar conta da aplicação prática do Decreto, para ver se foram achados pontos difíceis e controversos na aplicação ou não.

O Decreto entrou em vigor há mais de 10 anos e, sem dúvida, levou a mudanças significativas e concretas na organização da empresa. As pessoas jurídicas puseram modelos de comportamento padrão; aconteceram muitos processos de atribuição de responsabilidade com a imposição de sanções. A atribuição de responsabilidade é agora o resultado de muitos processos, assim que se tornou normal esse tipo de juízo no nosso ordenamento jurídico. A preocupação do que a criação de modelos formais fosse pra se tornar um ponto de apoio apenas pra evitar a responsabilidade foi amplamente descartada e isso tem prova nas muitas sanções impostas. Mas ainda não tem sido dissolvido, por enquanto, um ponto focal. O Decreto estabeleceu um mecanismo com finalidade essencialmente preventiva. Além da intenção das sanções, não pode ser negligenciada a ideia da prevenção, que é bem forte. Na verdade, poderíamos até dizer que o objetivo de prevenção é ainda mais forte do que o das sanções, como está demonstrado pelo fato de que um ente pode evitar a responsabilidade fornecendo modelos padrão de comportamento adequadamente implementados. Modelos, de fato, o propósito dos quais é inteiramente preventivo. Em vista desse forte 
impulso no caminho da prevenção, temos de nos perguntar se a introdução da responsabilidade do ente no sistema italiano teve como consequência aquela da diminuição dos crimes cometidos em nome e no interesse ou vantagem do mesmo ente. Não há dados estatísticos. De fato, parece que não houve um impacto a este respeito. O que, em parte, significa negar a própria razão da introdução da responsabilidade. Mas permanece a importância de ter imposto uma estrutura preventiva e, especialmente, de ter estabelecido uma responsabilidade coletiva, o que foi realmente apropriado. Trata-se, portanto, de um instrumento inicial de civilização dos comportamentos que, como tal, precisa de um tempo significativo para produzir frutos e efeitos.

\section{REFERÊNCIAS}

AA.VV. La responsabilità amministrativa degli enti. D.lgs. 8 giugno 2001. n. 231. Milano, 2002. 2003.

Responsabilità degli enti per i reati commessi nel loro interesse. In: CP,

La responsabilità della società per il reato dell'amministratore, a cura di Lancellotti. Torino, 2003.

. I modelli organizzativi ex D.lgs. n. 231/2001. Etica di impresa e responsabilità degli enti. Milano, 2005.

La responsabilità amministrativa delle società. Analisi del rischio reato e modelli di prevenzione. Milano, 2003.

Societas puniri potest. La responsabilità da reato degli enti collettivi. In: Atti del Convegno, Facoltà di Giurisprudenza e dal Dipartimento del diritto comparato e penale dell'Università di Firenze, 15-16.03.2002. Padova, 2003.

Alberti. Fondamenti aziendalistici della responsabilità degli enti ai sensi del d. lgs. n. 231 del 2001. In: Soc, 2002.

Alessandri. La legge delega n. 366 del 2001: un congedo dal diritto penale societário. In: CorG, 2001.

. Note penalistiche sulla nuova responsabilità delle persone giuridiche. In: RTDPE, 2002.

. Riflessioni penalistiche sulla nuova disciplina. In: La responsabilità amministrativa degli enti. Milano, 2002.

Amarelli. Mito giuridico ed evoluzione della realtà: il crollo del principio societas delinquere non potest. In: RTDPE, 2003.

. La responsabilità delle persone giuridiche e la repressione della criminalità organizzata transnazionale. In: Patalano (a cura di). Nuove strategia per la lotta al crimine organizzato transnazionale. Torino, 2003. 
La responsabilità penale delle persone giuridiche tra ostacoli dogmatici ed istanze di politica criminale. In AA.VV. Il nuovo sistema sanzionatorio del diritto penale dell'economia: decriminalizzazione e problema di effettività, a cura di De Vita. Napoli, 2002.

; D'Alessandro; De Vita. Il nuovo sistema sanzionatorio del diritto penale dell'economia: decriminalizzazione e problemi di effettività. Napoli, 2002.

Амато. Un regime diversificato per reprimere gli illeciti. In: GDir, 2001.

Ambrosetti. Efficacia della legge penale nei confronti delle persone. In: Ronco; Zanichelli (a cura di). La legge penale. Bologna, 2006.

Amodio. Prevenzione del rischio penale d'impresa e modelli integrativi della responsabilità degli enti. In: CP, 2005.

Arena; Oliviero. La responsabilità degli enti per illeciti dipendenti da reato. In: TR, $2,2001$.

Assumma. Principi generali della nuova disciplina. Modelli organizzativi dell'impresa e responsabilità dell'organo di controllo. Relazione al seminario studio su: La responsabilità in sede penale delle imprese e degli enti pubblici economici. La riforma dei reati societari. Roma, 11.12.2001.

Astrologo. "Interesse" e "vantaggio" quali criteri di attribuzione della responsabilità dell'ente nel d. lgs. 231/2001. In: IP, 2003.

BARBUTO. Responsabilità amministrativa della società per reati commessi a suo vantaggio. In: CeI, 2001.

BARTOLOMUcCi. Codici comportamentali di categoria, tra aspettative e reale portata normativa. In: DPSoc, 2003.

Responsabilità amministrativa dell'ente: l'adozione dei modelli organizzativi. In: DPSoc, 2002.

Responsabilità delle persone giuridiche ex d.lgs. n.23172001: notazioni critiche. In: Soc, 2005.

BASTIA. Implicazioni organizzative e gestionali della responsabilità amministrativa delle aziende. Relazione dattiloscritta, Convegno di studi, Societas puniri potest. La responsabilità da reato degli enti collettivi. Firenze, 15-16.03.2002.

BATtAGLini. Responsabilità penale delle persone giuridiche? In: RP, 1930.

BAvA. La responsabilità amministrativa ed il sistema di controllo interno. In: CeI, 2003.

Belli; ACQuARoli. La responsabilità delle persone giuridiche. In: [www.europalex/ kataweb.it]. 2001.

Bertonazzi. La responsabilità amministrativa degli enti (commento al d.lgs. 8/6/2001 n. 231). In: GDA, 2001.

Bricchetti. Società al debutto nel registro degli indagati. In: GDir, 07.07.2001.

BRICOLA. Il costo del principio "societas delinquere non potest" nell'attuale dimensione del fenomeno societario. In: RIDPP, 1970. 
Busson. Il commento ai codici di comportamento delle associazioni rappresentative degli enti. In: AA.VV. Societas puniri potest. La responsabilità da reato degli enti collettivi. Padova, 2003.

. Responsabilità patrimoniale e vicende modificative dell'ente. In: AA.VV. Responsabilità degli enti per illeciti amministrativi dipendenti da reato, a cura di Garuti. Padova, 2002. 2002.

CADoppi; LANZI. I nuovi reati societari (commentario al Decreto Leglisativo 11 aprile 2002, n. 61). Padova, 2002.

CALPECCHI. Funzione rieducatrice della pena e responsabilità amministrativa delle persone giuridiche. In: DCI, 2003.

CARACCIOLI. Osservazioni sulla responsabilità penale "propria" delle persone giuridiche. In: Studi in onore di Marcello Gallo. Scritti degli allievi. Torino, 2004.

. Responsabilità amministrativa degli enti-Ampliato l'elenco dei reati. In: F, 2001.

. Una riforma in linea con la realtà econômica. In: LP, 2002.

CARBOne. La nuova disciplina della responsabilità amministrativa delle società. In: DResp, 2002.

CARMONA. La responsabilità degli enti: alcune note sui reati presupposto. In: RTDPE. Padova, 2003.

Ceresa Gastaldo. Il "processo alle società" nel d. lgs. 8 giugno 2001 n. 231. Torino, 2002.

GaITo. Cod. proc. pen. Ipertestuale. Leggi Complementari. Torino, 2005.

Cocco. Lillecito degli enti dipendente da reato ed il ruolo dei modelli di prevenzione. In: RIDDP, 2004.

Conti. La responsabilità amministrativa delle persone giuridiche. Abbandonato il principio societas delinquere non potest. In: Tratt. Galgano, XXV. Padova, 2001.

Convi. Attribuzioni del giudice penale in materia di responsabilità degli enti. In: La responsabilità amministrativa degli enti. Milano, 2002.

D'Alfonso; FrAnZESE. I criteri di attribuzione della responsabilità amministrativa ed i modelli di organizzazione e gestione. In: RDImpr, 2001.

. La responsabilità amministrativa dell'ente. In: RDImpr, 2002, 1923.

D'ANDREA. La nuova responsabilità amministrativa a carico di società e associazioni. In: DPS, 2001.

Da Riva Grechi. Lillecito funzionale degli enti collettivi. In: GP, 2003.

De Angelis. Responsabilità patrimoniale e vicende modificative dell'ente (trasformazione, fusione, scissione, cessione d'azienda). In: Soc, 2001. 
De Felice. La responsabilità da reato degli enti collettivi. Parte prima. Principi generali e criteri di imputazione (d. lgs. 231/2001). Bari, 2003.

De Francesco. Disciplina penale societaria e responsabilità degli enti: le occasioni perdute dalla politica criminale. In: DPP, 2003.

. Lenigma del tentativo: vicende sistematiche ed interrogativi politico-criminali. In: LP, 2002.

. Il principio della responsabilità penale nel quadro delle scelte di criminalizzazione - Suggestioni teleologiche ed esigenze politico criminali nella ricostruzione dei presupposti costituzionali di riconoscibilità dell'illecito penale. In: RIDPP, 1996.

. La responsabilità della societas: un crocevia di problematiche per un nuovo "modello" repressivo. In: LP, 2003.

De Maglie. In difesa della responsabilità penale delle persone giuridiche. In: LP, 2003. 2002.

L'etica e il mercato. La responsabilità penale della società. Milano: Giuffrè,

Principi generali e criteri di attribuzione della responsabilità. In: $L a$ disciplina della responsabilità amministrativa delle persone giuridiche e delle associazioni. In: DPP, 2001.

. Responsabilità delle persone giuridiche: pregi e limiti del d. lgs. $n$. 231/2001. In: DResp, 2002.

. Verso un codice penale europeo: la responsabilità penale delle persone giuridiche.

; Piergallini; Busson; Ferrua; Nuzzo. La disciplina della responsabilità amministrativa delle persone giuridiche e delle associazioni. In: DPP, 2001.

De Marzo. La delega al Governo per la disciplina della responsabilità amministrativa delle persone giuridiche e degli enti privi di personalità giuridica. In: CorG, 2001.

. Il d. lgs. n. 231/2001: responsabilità patrimoniale e vicende modificative dell'ente. In: CorT, 2001.

. Le sanzioni amministrative: pene pecuniarie e sanzioni interdittive. In: Soc, 2001.

De Simone. Persone giuridiche e diritto penale: i paradigmi di responsabilità ipotizzabili. In: AA.VV. Offensività e colpevolezza. Verso un codice penale modello per l'Europa, a cura di Cadoppi. Padova, 2002.

. I profili sostanziali della responsabilità c.d. amministrativa degli enti; la "parte generale" e la "parte speciale" del d. lgs. 8 giugno 2001 n. 23. In: La responsabilità degli enti per i reati commessi nel loro interesse. In: CP, 2003.

I profili sostanziali della responsabilità c.d. amministrativa degli enti: la "parte generale" e la "parte speciale" del D. Lgs. 8/6/2001 n. 231. In: AA.VV. 
Responsabilità degli enti per illeciti amministrativi dipendenti da reato (a cura di Garuti). Padova, 2002.

La responsabilità da reato degli enti nel sistema sanzionatorio italiano: alcuni aspetti problematici. In: RTDPE, 2004.

. La responsabilità da reato dell'impresa nel sistema italiano: alcune osservazioni rapsodiche e una preliminare divagazione comparatistica. In: PALAzzo (a cura di). Societas puniri potest. La responsabilità da reato degli enti collettivi. Padova, 2003.

De Vero. I reati societari nella dinamica evolutiva della responsabilità ex crimine degli enti collettivi. In: RIDPP, 2003.

. La responsabilità dell'ente collettivo dipendente da reato: criteri di imputazione e qualificazione giuridica.

. Struttura e natura giuridica dell'illecito di ente collettivo dipendente da reato. In: RIDPP, 2001.

Delmas; Marty. Il CI delle norme penali per la protezione degli interessi fiscali dell'Unione Europea. In: QG, 2000.

Di CEnso. Le disposizioni di attuazione e di coordinamento: un capitolo tutt'altro che marginale. In: La responsabilità amministrativa degli enti. Milano, 2002.

Di Pinto. La responsabilità amministrativa da reato degli enti. Profili penali sostanziali e ricadute sul piano civilistico. Torino, 2003.

Di Geronimo. Responsabilità da reato degli enti: l'adozione di modelli organizzativi post factum ed il commissariamento giudiziale nell'ambito delle dinamiche cautelari. Nota a ord. Gip. Trib. Roma, 04.04.2003. In: CP, 2004.

Dolcini. Principi costituzionali e diritto penale alle porte del terzo millennio. Riflessioni in tema di fonti, diritto penale minimo, responsabilità degli enti e sanzioni. In: RIDPP, 1999.

D'URSO. Verso una novità "antica": la responsabilità penale della persona giuridica. In: Quad. G, XXII, 2002.

FAlzeA. La responsabilità penale delle persone giuridiche. In: La responsabilità penale delle persone giuridiche in diritto comunitario. Milano, 1981.

FARINA. I reati societari e la responsabilità delle persone giuridiche. In: BBTC, 2004.

FERRUA. Le insanabili contraddizioni nella responsabilità dell'impresa. In: DeG, 2001.

Fiandaca; Musco. Diritto penale, parte generale. Bologna, 2001.

FIDELBO. Introduzione di un sistema di responsabilità penale (o amministrativa) delle persone giuridiche e ricadute sul piano processuale. In: CP, 1999.

FIGURATI. Responsabilità amministrativa delle persone giuridiche: aspetti lavoristici. In: GiP, 2002. 
FIORELla. Principi generali e criteri di imputazione all'ente della responsabilità amministrativa. In: La responsabilità della società per il reato dell'amministratore, a cura di Lancellotti. Torino, 2003.

Le sanzioni amministrative pecuniarie e le sanzioni interdittive. In: Responsabilità degli enti per i reati commessi nel loro interesse. In: CP, 2003.

FofFANI. Responsabilità delle persone giuridiche e riforma dei reati societari. In: Societas puniri potest, la responsabilità da reato degli enti collettivi. In: Palazzo (a cura di). Padova, 2003.

Foglia; Manzillo. Responsabilità dell'ente: amministrativa, penale o "tertium genus”? In: DPS, 2003.

. Verso la configurazione della responsabilità penale per la persona giuridica. In: DPP, 2000.

Folla. Le sanzioni pecuniarie. In: La responsabilità amministrativa degli enti. Milano, 2002.

Forlenza. Con l'avvicinamento tra persone fisiche e giuridiche un primo passo verso il completamento della delega. In: GDir, 2001.

FORMICA. La responsabilità amministrativa degli enti e i reati societari. In: La riforma dei reati societari. Atti del seminario, Macerata, 21.03.2003. Milano, 2004.

Fortunato; Reboa. Limplementazione dei modelli organizzativi e di gestione ex $d$. lgs. n. 231/2001. In: RdoC, 2004.

Frignani; Grosso; Rossi. I modelli di organizzazione previsti dal d. lgs. n. 231 del 2001 sulla responsabilità degli enti. In: Soc, 2, 2002.

Gallo. Appunti di diritto penale. Torino: Giappichelli, 2006. vol. IV.

La persona umana nel diritto penale. In: RIDP, 1956.

GARGANI. Imputazione di reato agli enti collettivi e responsabilitàpenale dellìntraneo: due piani irrelati? In: DPP, 2002.

GARUTI. Responsabilità degli enti per illeciti amministrativi dipendenti da reato. Padova, 2002.

Gennai; Traversi. La responsabilità degli enti per gli illeciti amministrativi dipendenti da reato. Milano, 2001.

Giarda; Seminara. I nuovi reati societari: diritto e processo. Padova, 2002.

. Un sistema ormai a triplo binario: la giurisdizione penale si amplia. In: La responsabilità amministrativa degli enti. Milano, 2002.

. Societas delinquere potest: o no? In: AA.VV. La responsabilità amministrativa degli enti. Milano, 2002.

Giarda; ManCuso. Nuove ipotesi di responsabilità amministrativa degli enti: futuribili ma non troppo. In: La responsabilità amministrativa degli enti. Milano, 2002. 
Giavazzi. Le sanzioni interdittive e la pubblicazione della sentenza penale di condanna. In: La responsabilità amministrativa degli enti. Milano, 2002.

GiUnTA. Attività bancaria e responsabilità ex crimine degli enti collettivi. In: RIDPP, 2004.

I nuovi illeciti penali e amministrativi riguardanti le società commerciali. Commentario del d. lgs. 11 aprile 2002 n. 61. Torino, 2002.

GRASSO. La responsabilità amministrativa dipendente da reato delle persone giuridiche, delle società e delle associazioni prive di personalità. In: CeI, 2001.

Graziano. I modelli organizzativo preventivi e l'esperienza dei "compliance program”. In: DPS, 6, 2002.

. La responsabilità delle società alla luce della nostra tradizione giuridica. In: DPS, 2001.

La responsabilità "penale-amministrativa" delle persone giuridiche. In: DPS, 2002.

Grosso. Responsabilità penale delle persone giuridiche (osservazioni in margine al volume di C. De Maglie). In: RIDPP, 2003.

. Sanzioni amministrative pecuniarie: criteri di commisurazione delle sanzioni, casi di riduzione. In: La nuova disciplina della responsabilità amministrativa delle persone giuridiche e delle società. Milano, 2001.

Sulla costituzione di parte civile nei confronti degli enti collettivi chiamati a rispondere ai sensi del d. lgs, n. 231 del 2001 davanti al giudice penale. In: RIDPP; GuERNELLI. La responsabilità delle persone giuridiche nel diritto penale-amministrativo interno dopo il D. legisl. 8 giugno 2001, n. 231. In: StI. Padova, 2001.

Guerrini. Commento all'art. 3. In: Giunta (a cura di). I nuovi illeciti penali ed amministrativi riguardanti le società commerciali. Torino, 2002.

. Colpa d'organizzazione e modelli di prevenzione del rischio penale d'impresa: riflessioni ai margini del d. lgs. 231/2001. In: [www.dirittoegiustiziaonline. it/penale/impresa.htm].

. La responsabilità penale delle persone giuridiche. In: Soc, 1993.

InSOlERA. Nozione di responsabilità individuale e collettiva. In: IP, 1996.

Izzo. Sindacato giudiziario sull'idoneità dei modelli organizzativi. In: F, 2002.

LECCESE. Responsabilità delle persone giuridiche e delitti con finalità di terrorismo o eversione dell'ordine democratico (art. 25 quater, D. Lgs. n. 231 del 2001). In: RTDPE, 2003.

Lo Russo. La responsabilità da reato delle persone giuridiche: profili processuali del d. lgs. 8 giugno 2001 n. 231. In: CP, 2002.

LotTinı. Il sistema sanzionatorio. In: AA.VV. La responsabilità degli enti per illeciti amministrativi dipendenti da reato, a cura di Garuti. Padova, 2002. 
Il sistema sanzionatorio. In: Responsabilità degli enti per i reati commessi nel loro interesse. In: CP, 6, 2003.

Magnante. La responsabilità amministrativa delle società per i reati commessi dai propri dipendenti. In: RDImpr, 2001.

. La responsabilità delle società per reati commessi dai dipendenti, dubbi interpretativi e di legittimità costituzionale. In: RDImpr, 2002.

MAIELlo. La natura (formalmente amministrativa, ma sostanzialmente penale) della responsabilità degli enti nel d. lgs. n. 231/2001: una "truffa delle etichette" davvero innocua? In: RTDPE, 2002.

Malinconici. Identificazione dei soggetti a cui è attribuita la responsabilità amministrativa: enti con personalità giuridica, enti pubblici economici, società, associazioni anche prive di personalità giuridica. In: La nuova disciplina della responsabilità amministrativa delle persone giuridiche e delle società. Milano, 2001.

Manacorda. Corruzione internazionale e tutela penale degli interessi comunitari (commento alla L. 29/9/00 n. 300). In: DPP, 2001.

ManNa. La c.d. responsabilità amministrativa delle persone giuridiche: il punto di vista del penalista. In: CP, 2003.

La c.d. responsabilità amministrativa delle persone giuridiche: un primo sguardo d'insieme. In: RTDPE, 2002.

La responsabilità delle persone giuridiche: il problema delle sanzioni. In: RTDPE, 1999.

MARrA. Note a margine dell'art. 6 ddl n. 3915-S contenente una "delega al Governo per la disciplina della responsabilità delle persone giuridiche”. In: RTDPE, 1999.

Marinucci. "Societas puniri potest": uno sguardo sui fenomeni e sulle discipline contemporanee. In: RIDPP, 2002.

Mattei. Modelli organizzativi e organismo di controllo come strumenti di prevenzione. In: Le monografie di diritto e pratica delle società, 2002.

MAUGERI. Le moderne sanzioni patrimoniali tra funzionalità e garantismo. Milano, 2001.

Melchionda. Brevi appunti sul fondamento "dogmatico" della nuova disciplina sulla responsabilità degli enti collettivi. In: Palazzo (a cura di). Societas puniri potest. La responsabilità da reato degli enti collettivi. Padova, 2003.

Michelini. Responsabilità delle persone giuridiche e normativa internazionale multilaterale. In: QG, 2002.

Miedico. I reati che determinano la responsabilità amministrativa dell'ente. In: La responsabilità amministrativa degli enti. Milano, 2002.

Mifsud Mariano. Il d.lgs. $n$. 231/01 sulla responsabilità amministrativa delle imprese ed il sistema sanzionatorio disciplinare. In: RDImpr, 2002. 
. Responsabilità amministrativa delle imprese. In vigore le disposizioni regolamentari. In: RDImpr, 2003.

La responsabilità degli enti per illeciti amministrativi dipendenti da reato ed i modelli di organizzazione e gestione. In: RDImpr, 2002.

Musco. Le imprese a scuola di responsabilità tra pene pecuniarie e misure interdittive, il reato del dirigente si "duplica” nell'illecito amministrativo. In: DeG, 2001. 2002.

. Responsabilità amministrativa delle persone giuridiche. In: Giusto proc.,

La responsabilità da reato degli enti collettivi. Relazione inedita, XIX Congresso nazionale della Associazione per gli scambi culturali tra i giuristi italiani e tedeschi. Bari, 10-12.10.2002.

NannucCI. Responsabilità delle società: d.lgs. 8 giugno 2001, n. 231. In: F, 2004.

Nisco. Responsabilità amministrativa degli enti: riflessioni sui criteri ascrittivi "soggettivi" e sul nuovo asserto delle posizioni di garanzia nelle società. In: RTDPE, 2004.

Nocerini. La responsabilità amministrativa dei soggetti in posizione di vertice e dei dirigenti. In: La nuova disciplina della responsabilità amministrativa delle persone giuridiche e delle società. Milano, 2001.

Nuzzo. Primi appunti sugli aspetti probatori e sulle decisioni finali concernenti l'illecito amministrativo dipendente da reato. In: ANPP. Piacenza, 2001.

Padovani. Diritto penale. Milano, 2002.

Palazzo. Societas puniri potest. La responsabilità da reato degli enti collettivi. Padova, 2003.

Paliero. Il d. lgs. 8/6/2001, n. 231: da ora in poi, societas delinquere (et puniri) potest. In: CorG, 7, 2001.

. Problemi e prospettive della responsabilità penale dell'ente nell'ordinamento italiano. In: RTDPE, 1996.

La responsabilità delle persone giuridiche: profili generali e criteri di imputazione. In: AA.VV. Il nuovo diritto penale delle società, a cura di Alessandri. Milano, 2002.

. La responsabilità penale della persona giuridica nell'ordinamento italiano: profili sistematici. In: Societas puniri potest. La responsabilità da reato degli enti collettivi, a cura di Palazzo. Padova, 2003.

PAlmieri. Modelli organizzativi, diligenza e "colpa" amministrativa dell'impresa. In: DPS, 2001.

. "Societas delinquere non potest": un concetto da superare. In: DP, 2001.

PARISI. Riflessioni in tema di responsabilità penale delle persone giuridiche. In: RP, 1999.

Pasculli. Eccessi di delega e questioni insolute nel d. lgs. n. 231/01. In: RP, 2002. . Il principio di legalità: struttura, finalità, applicazioni. In: RP, 2001. 
. La responsabilità "da reato" degli enti collettivi nell'ordinamento italiano. Profili dogmatici ed applicativi. Bari, 2005.

. Rilevanza della delega di funzioni: riflessioni in tema di responsabilità diretta delle persone giuridiche. In: RTDPE, 2003.

Patrono. Verso la soggettività penale di società ed enti. In: RTDPE, 2002.

Pecorella. Principi generali e criteri di attribuzione della responsabilità. In: AA.VV. La responsabilità amministrativa degli enti. Milano, 2002.

Pelissero. La responsabilizzazione degli enti alla ricerca di un difficile equilibrio tra modelli "punitivi" e prospettive di efficienza. In: LP, 2003.

; FIDELBO. Il commento alla legge delega, articolo per articolo. In: LP, 2001.

; __ La "nuova" responsabilità amministrativa delle persone giuridiche. In: LP. Torino, 2002.

Piergallini. La disciplina della responsabilità amministrativa delle persone giuridiche e delle associazioni. Sistema sanzionatorio e reati previsti dal codice penale. In: DPP, 2001.

. La responsabilità amministrativa delle persone giuridiche. In: AA.VV. I nuovi reati societari: diritto e processo. Padova, 2002.

La responsabilità "da reato" degli enti nell'ordinamento italiano. In: AA.VV. Societas delinquere et puniri non potest. Riflessioni sul recente (contrastato) superamento di un dogma. In: QG, 2002.

. La riforma dei reati societari. Atti del seminario, Macerata, 21.03.2003. Milano, 2001.

Sistema sanzionatorio e reati previsti dal codice penale. In: DPP, 2001.

. Societas delinquere et puniri non potest: la fine tardiva di un dogma. In: RTDPE, 2002.

Platania. L'evidenziazione contabile delle sanzioni ex d. lgs. n. 231 del 2001 e vicende modificative dell'ente. In: Soc, 2002.

Pulitanò. Responsabilità amministrativa per i reati delle persone giuridiche. In: ED, VI agg. Milano, 2002. 2002.

. La responsabilità "da reato" degli enti: i criteri di imputazione. In: RIDPP,

La responsabilità degli enti per i reati commessi nel loro interesse. Atti del Convegno, Roma, 30.11-01.12.2001. In: CP, 2003.

PutinAti. Art. 3. In: AA.VV. I nuovi reati societari, a cura di Lanzi, Cadoppi. Milano, 2002.

Razzante; Toscano. La responsabilità amministrativa delle persone giuridiche. Profili teorici e partici connessi all'applicazione del d.lgs. 8/6/2001 n. 231. Torino, 2003. 
Ricciuto. Responsabilità patrimoniale ed eventi modificativi dell'ente. Relazione al Convegno, La responsabilità da reato degli enti collettivi, Nule (ss), 30.11.2002.

Riondato. Prevenzione dei reati riconducibili alla politica dell'ente e personalità della responsabilità penale dell'ente (D. lgs. 8/6/01 n. 231). In: RTDPE, 2003.

RomANo. La responsabilità amministrativa degli enti, società o associazioni: profili generali. In: RS, 2002.

RONCO; RoRdorf. I criteri di attribuzione della responsabilità. I modelli organizzativi e gestionali idonei a prevenire i reati. In: Soc, 2001.

Prime (e sparse) riflessioni sulla responsabilità amministrativa degli enti collettivi per reati commessi nel loro interesse o a loro vantaggio. In: AA.VV. La responsabilità amministrativa degli enti D.lgs. 8 giugno 2001, $n$. 231. Milano, 2002.

Rossi. Responsabilità amministrativa-penale delle persone giuridiche (profili sostanziali). In: Digesto Ipert., 2003.

Rubboli; Bramieri; Begaglia; Bogliacino. La responsabilità amministrativa delle società. Analisi del rischio e modelli di prevenzione. Milano, 2003.

RUGGIERO. Brevi note sulla validità della legge punitiva amministrativa nello spazio e sulla efficacia del modello di organizzazione nella responsabilità degli enti derivanti da reato. In: Diritto penale dell'economia, 2004.

. Capacità penale e responsabilità degli enti. Una rivisitazione della teoria dei soggetti nel diritto penale. Torino, 2004.

SACERDOTI. Responsabilità d'impresa e strumenti internazionali anticorruzione. Milano, 2003.

SANTI. La responsabilità delle società e degli enti. Milano, 2004.

SANTORIEllo. Il nuovo diritto penale delle società. Torino, 2003.

SANTAMARIA. La responsabilità amministrativa nel d.lgs. n. 231/2001. In: F, 2001.

SELVAGgi. La responsabilità penale della persona giuridica: un dibattito europeo. In: CP, 1999.

SFAMENI. La responsabilità delle persone giuridiche: fattispecie e disciplina dei modelli di organizzazione, gestione e controllo. In AA.VV. La responsabilità amministrativa degli enti. Milano, 2002.

. Responsabilità patrimoniale e vicende modificative dell'ente. In: La responsabilità amministrativa degli enti. Milano, 2002.

La società non potrà più "mascherare" i reati commessi nel suo interesse. Principio di responsabilità fondato sulla soggettività giuridica. In: DeG, 2001.

Spagnolo. I meccanismi sanzionatori previsti dal d. lgs. n. 231 del 2001. Relazione al convegno, Responsabilità penale o amministrativa delle persone giuridiche? Lecce, 9-10.11.2001.

STELla. Criminalità d’impresa:lotta di sumo e lotta di judo. In: RTDPE, 1998. 
. Giustizia e modernità. Milano, 2001.

STORTONI. I reati per i quali è prevista la responsabilità degli enti. In: AA.VV. $\mathrm{La}$ responsabilità degli enti per illeciti amministrativi dipendenti da reato, a cura di Garuti. Padova, 2002.

TRavi. La responsabilità della persona giuridica nel D. Lgs. n. 231/2000: prime considerazioni di ordine amministrativo. In: Soc, 2001.

Vervaele. Responsabilità penale delle persone giuridiche. In: Verso un codice penale moderno per l'Europa. Offensività e colpevolezza, a cura di Cadoppi. Padova, 2002.

VIGNOLI. Societas delinqueri potest: profili critici di un'autonoma responsabilità dell'ente collettivo. In: DPP, 2004.

VinciguerRa; Rossi; Ceresa Gastaldo. La responsabilità dell'ente per il reato commesso nel suo interesse. Padova, 2004.

ZANALDA. Nuovi profili di responsabilità della persona giuridica nel processo penale. In: F, 2001.

. La responsabilità "parapenale" delle società. In: All. n. 5 a F, n. 416, 2001. ; Barcellona. La responsabilità amministrativa delle società e i modelli organizzativi. Milano, 2002.

\section{Pesouisas do Editorial}

\section{Veja também da mesma Autora}

- A extradição: entre escolhas políticas e atuação judiciária, de Maristella Amisano Tesi RDBras 1/487. 